\title{
Childhood Brain Anaplastic Astrocytoma
}

National Cancer Institute

\section{Source}

National Cancer Institute. Childhood Brain Anaplastic Astrocytoma. NCI Thesaurus. Code C6252.

An anaplastic astrocytoma that arises from the brain and occurs during childhood. 